\title{
Os mercados de hortifrúti em Santa Maria (RS) - um estudo sobre os tipos de produtores e os canais de comercialização
}

\author{
Janaína Balk Brandão \\ Programa de Pós Graduação em Extensão Rural, Universidade Federal de Santa \\ Maria - Santa Maria - Rio Grande do Sul - Brasil \\ ORCID: http://orcid.org/0000-0002-3044-3473
}

\section{Sérgio Schneider}

Departamento de Sociologia e membro permanente dos Programas de PósGraduação em Desenvolvimento Rural e de Sociologia da UFRGS - Porto Alegre Rio Grande do Sul - Brasil

ORCID: https://orcid.org/0000-0002-4353-6732

\section{Humberto Davi Zen}

Programa de Pós Graduação em Extensão Rural, Universidade Federal de Santa Maria - Santa Maria - Rio Grande do Sul - Brasil

ORCID: https://orcid.org/0000-0002-6005-660X

\section{Gustavo Pinto da Silva}

Colégio Politécnico de Santa Maria, Universidade Federal de Santa Maria - Santa Maria - Rio Grande do Sul - Brasil

ORCID: https://orcid.org/0000-0002-8567-7664

\section{Resumo}

Este artigo busca ampliar a compreensão do abastecimento de hortifrútis por meio de um estudo dos mercados em Santa Maria/Rio Grande do Sul no qual os principais critérios adotados na análise são: tipos de produtor, os diferentes canais de comercialização e a característica do mercado utilizado. Foram abordados 91 estabelecimentos produtores e constatou-se que 50,5\% são Pequenos Produtores de Mercadorias, 39,5\% Produtores Simples de Mercadorias e 11\% Produtores Capitalistas de Mercadorias. Há tendência para mercados amparados em canais de nível zero, com encurtamento da cadeia, destacando-se as feiras, acessadas por $72 \%$ dos produtores. Em $49 \%$ dos casos, emprega-se apenas um canal de comercialização, em $32 \%$, dois, em $16 \%$, três, e somente $2 \%$ utilizam quatro canais. Os Mercados de Proximidade (MP) são mais frequentemente acessados pelos produtores, seguidos por Mercados Locais e Territoriais (MLT), enquanto Mercados Convencionais (MC) possuem um número mais limitado de produtores envolvidos. Sugere-se uma nova categorização de produtor, o Produtor Rentista, bem como, aponta-se que uma maior autonomia do produtor dependerá do acesso a mais canais de comercialização e maior controle para apropriação do valor gerado. Embora haja diversidade de canais nos quais os 
agricultores de hortifrúti de Santa Maria/RS se inserem, verifica-se maior dependência dos MP e MLT, demonstrando como a cadeia produtiva analisada é restrita ao contexto local.

Palavras-chave: Feiras. Pequeno Produtor de Mercadorias. Mercados de Proximidade.

\section{Fruit and vegetable markets in Santa Maria (RS): study of the types of producers and marketing channels}

\section{Abstract}

This article seeks to broaden the understanding of the supply of fruit and vegetables through a study of the markets in Santa Maria/Rio Grande do Sul in which the main criteria adopted in the analysis are: types of producer, the different marketing channels and the characteristics of the market used. In Ninety-one growers in Santa Maria/RS were approached, it was found that $50.5 \%$ of producers are Small Commodity Producers, $39.5 \%$ Simple Commodity Producers and $11 \%$ Capitalist Commodity Producers. There is a tendency for markets supported by zero-level channels, with chains hortening, especially Farmers Markets, which accessed by $72 \%$ of producers. In $49 \%$ of cases, only one marketing channel is explored, in $32 \%$, two, in $16 \%$, three, and only $2 \%$ use four channels. Proximity Markets (PM) are most of ten employed by producers, followed by Local and Territorial Markets (MLT), while Conventional Markets (MC) have more limited number of producers involved. We suggest a new producer category, the Rentier Producer, as well as we point out that greater producer autonomy will depend on access to more marketing channels and on a greater control for appropriation of the generated value. Although there are diverse channels where farmers from Santa Maria/RS are inserted, there is greater dependence on MP and MLT, demonstrating how the analyzed production chain is restricted to the local context.

Keywords: Farmers Markets; Small Commodity Producers; Proximity Markets.

\section{Los mercados hortícolas en Santa Maria (RS): un estudio sobre tipos de productores y canales de comercialización}

\section{Resumen}

Este artículo busca ampliar la comprensión del suministro de frutas y verduras a través de un estudio de los mercados en Santa Maria/Rio Grande del Sul en el que los principales criterios adoptados en el análisis son: tipos de productores, los diferentes canales de comercialización y las características del mercado utilizado. En los noventa y un establecimientos productores en Santa Maria/ RS que fueron abordados se encontró que el $50.5 \%$ de los productores son pequeños productores de productos básicos, $39.5 \%$ productores de productos básicos simples y $11 \%$ productores de productos básicos capitalistas. Existe una tendencia hacia mercados respaldados por canales de nivel cero, con un acortamiento de la cadena, especialmente ferias, al que accede el $72 \%$ de los productores. En el $49 \%$ de los casos, solo se emplea un canal de comercialización, el 32\%, dos en el $16 \%$, tres y solo el $2 \%$ usa cuatro canales. Los mercados de proximidad (PM) son los que más acceden los productores, seguidos por los mercados locales y territoriales (MLT), mientras que los mercados convencionales $(M C)$ tienen un número más limitado de productores involucrados. Se sugiere una nueva categorización del productor, el Productor Rentista, además de señalar que una mayor autonomía del productor dependerá del acceso a más canales de comercialización, así como un mayor control para la apropiación del valor generado. Aunque hay diversidad de canales donde se insertan los agricultores de Santa Maria/ RS, existe una mayor dependencia de MP y MLT, lo que demuestra cómo la cadena de producción analizada se restringe al contexto local.

Palabras clave: Ferias. Pequeño productor de bienes. Mercados de proximidad. 


\section{INTRODUÇÃO}

Este artigo se dedica a compreender as lacunas existentes nos estudos dos mercados agroalimentares, especialmente de Hortifrútis (HF), de forma a incorporar na análise três dimensões, quais sejam: o tipo de agricultor, os canais e os tipos de mercados. Considera-se que esta perspectiva analítica pode representar um avanço no estudo dos mercados, já que contribuem para interpretar os processos e dinâmicas de troca e intercâmbio mercantil que vem sendo desenvolvidas por produtores e consumidores e suas interações com os mercados dominantes, além de explorar suas contribuições para os estudos dos mercados agroalimentares (CASSOL; SALVATE; SCHNEIDER, 2016).

A compreensão dos mercados agroalimentares de HF no Brasil passa por uma time line, cujo marco foi a implantação das Centrais de Abastecimento (CEASAs) na década de 70, que visavam garantir o abastecimento alimentar de grandes centros urbanos, facilitar a logística e a padronização e classificação dos produtos, além de aperfeiçoar os mecanismos de formação de preços, entre outros fatores (ZEITUNE, 2011).A segunda grande transformação foi representada pela ascensão das redes de varejo na comercialização de hortifrútis, que ganhou força a partir do início dos anos 80, iniciando-se pelos Estados Unidos e Europa, e posteriormente em países emergentes (SINI, 2014). Aproximadamente 70\% dos hortifrútis in natura chegam ao consumidor final por meio de super/hipermercados, enquanto os $30 \%$ remanescentes do mercado são supridos por fruteiras, minimercados, feiras convencionais e agroecológicas, entre outros (ABRAS, 2016). A qualidade e diversidade de produtos, além de bom preço e apelo à vida saudável foram e ainda são fatores essenciais ao sucesso desta estratégia (SOUZA FILHO; BONFIM, 2013).

A terceira fase se consolidou internacionalmente no início dos anos 2000, com consumidores mais perceptivos a respeito da segurança e da qualidade, em um movimento cuja denominação mais ampla foi a de qualityturn (GOODMAN, 2003; HASTUTI, 2007). Além da crescente associação entre uma boa alimentação e estilo de vida mais saudável, no momento da decisão da compra de hortifrútis, leva-se em conta percepções a respeito de valores e necessidades pessoais, segurança alimentar, identificação com o local de origem da produção e impactos econômicos, sociais e ambientais (AHUMADA; VILLALOBOS, 2009; DOWD; BURKE, 2013). Esse panorama recente tem direcionando o abastecimento alimentar para arranjos mais pautados em circuitos curtos de fornecimento, o que contribui para criar oportunidades de mercado a produtores de pequeno e médio porte para além de mercados de nicho, possibilitando sua inserção em mercados mais significativos, como restaurantes, mercados institucionais e até mesmo o grande varejo (CUNHA, 2015; SOUZA FILHO; BONFIM, 2013).

Nesse contexto, o foco deste estudo está nas relações entre os agentes da cadeia produtiva de $\mathrm{HF}$, que ganhou complexidade em resposta às modificações ocorridas na conjuntura de mercado e nos hábitos e comportamento dos consumidores (SOUZA FILHO; BONFIM, 2013; MELO e VILELA, 2007). Isso fez com que toda a cadeia de suprimentos de HF tenha se organizado para ganhar eficiência, considerando, especialmente, sua alta perecibilidade (BRANDÃO; ARBAGE, 2016). Da perspectiva dos consumidores, há uma crescente preocupação com o meio 
ambiente e outros atributos sociais e éticos para sua escolha de consumo (KASRIEL, 2016), o que levará as empresas a reagir, ligando valores e símbolos ao alimento a fim de engajar consumidores em longo prazo (BRUNORI et al., 2016). Do ponto de vista produtivo, a modernização da agricultura e dos processos logísticos permitiu aumentar a oferta de alimentos não só a um preço mais baixo, mas também, para regiões distantes das áreas de produção, o que acabou transformando aspectos sociais, econômicos e ambientais do sistema de produção agroalimentar brasileiro (SCARABELOT; SCHNEIDER, 2012).

Simultaneamente, várias formas de abastecimento têm conseguido levar o alimento até o consumidor, o que inclui canais longos ou curtos (KOTLER, 2006) e resulta em canais de abastecimento mais ou menos complexos, enfatizando que a distância entre produção e consumo afetam significativamente a qualidade do produto distribuído (ACCORSI et al., 2016). Na produção e distribuição de alimentos, o que se vivencia são processos simultâneos de maior concentração e integração global e, ao mesmo tempo, essa distribuição apresenta resistência em decorrência de novas relações emergentes entre produtor e consumidor (SCHERMER, 2015). Assim, os mercados modernos aumentaram a relevância das funções relacionadas à cadeia de fornecimento de alimentos não apenas relacionado ao cultivo e o processamento de alimentos, mas também ao empacotamento, armazenamento, distribuição, controle e monitoramento da qualidade do produto em todo o seu ciclo de vida (ACCORSI et al., 2016).

Procurando auxiliar na compreensão das formas de abastecimento de perecíveis, o objetivo deste artigo é identificar os canais e os mercados agroalimentares acessados pelos diferentes tipos de produtores de hortifrúti no município de Santa Maria/Rio Grande do Sul. Pondera-se que a oferta de alimentos com origem regional pode afetar de maneira significativa a melhoria da qualidade dos alimentos, além de dinamizar a economia e estimular o desenvolvimento de determinados territórios. Isso justifica a importância de pesquisas empíricas com recorte geográfico local, alicerçadas na noção teórica de SAG que, por meio da elaboração de cenários normativos e exploratórios da atividade e da identificação de oportunidades e necessidades para cada elo da cadeia produtiva, servem como base para políticas públicas e projetos privados (CAMARGO et al., 2014). Do ponto de vista teórico, busca-se verificar nos casos estudados: I) a lógica proposta por Kotler $(1998,2006)$, com base no número de canais de comercialização utilizados; II) testar a tipificação dos agricultores de Ploeg (2006), por meio da análise das características sócio-econômico-produtivas; e, III) verificar a pertinência da classificação de mercados proposta por Schneider (2016).

Além desta introdução o artigo está organizado em mais cinco seções. A segunda seção tem por objetivo explorar a noção de cadeia alimentar, como também os conceitos de mercados e canais de comercialização. A terceira seção recupera os elementos metodológicos utilizados, a quarta seção apresenta os principais resultados, organizando-os em duas subseções. A quinta seção traz as considerações finais. 


\section{ENCADEAMENTO DISTRIBUTIVO E OS MERCADOS AGROALIMENTARES}

O Sistema Agroalimentar (SGA) é o conjunto formado por todas as cadeias produtivas dedicadas à produção de alimentos, cuja demanda de produtos não é caracterizada apenas pelo critério de quantidade/preço e oferece o devido lugar à economia da qualidade (WILKINSON,2008). Para caracterização de um SAG, é necessário identificar as suas atividades e participantes (estrutura), bem como as relações técnicas e socioeconômicas envolvidas (funcionamento) (ROESSING, 2002). Especificamente, a análise da estrutura consiste na caracterização técnica e socioeconômica dos atores diretamente envolvidos, o que implica na necessidade de identificar os elos de uma cadeia produtiva e na busca por entender a dinâmica e características das relações entre cada grupo (ROESSING, 2002). Uma cadeia produtiva é uma rede de interdependências estabelecida dentro de uma dimensão geográfica entre empresas e agentes que têm entre si um fluxo de bens e serviços, objetivando a satisfação da demanda de consumidores para um determinado produto (ZYBERSZTAJN, 2000; NEVES et al., 2017).

Nesse âmbito, as cadeias produtivas agroalimentares tornaram-se recentemente objeto de maior interesse de consumidores, empresas, organizações governamentais e acadêmicos, uma vez que a eficiência produtiva, distributiva e ambiental está constantemente sob análise (ALLAOUI et al., 2018). Em especial, as diferentes formas de organização e gerenciamento das cadeias suprimentos (HUGO, 2018) dentro das cadeias produtivas têm se mostrado uma forma interessante de analisar as configurações alimentares, seja por meio de critérios de eficácia ambiental (ALLAOUI et al., 2018), social e econômica (ACCORSI et al.,2018; BRANDÃO;ARBAGE, 2016), ou até mesmo de saúde pública (SAZVAR; RAHMANI; GOVINDAN, 2018).

Cadeias de suprimentos de alimentos na Índia, e em outros países em desenvolvimento, tipicamente são longas e fragmentadas, envolvendo múltiplos produtores de pequeno porte que entregam produtos a elos intermediários (GARG; SHARMA; SHUKLA, 2018). O produto, então, move-se para comerciantes, atacadistas e, possivelmente, para várias camadas de distribuição de varejo. Essas cadeias são caracterizadas por possuir várias etapas de manuseio de produtos, fluxos de informações insuficientes e uma predominância de transações via mercado spot, em detrimento de estruturas de governança híbridas ou hierárquicas (GARG; SHARMA; SHUKLA, 2018). Por outro lado, estudos- como o caso da Áustria - indicam que é possível identificar uma mudança de todo o SAG de "comida do nada" para "comida daqui", especialmente pelo surgimento de redes alimentares alternativas através do apelo político ao patriotismo do consumidor, que redirecionou para um posicionamento sustentado por cadeias de varejo com produtos alimentícios regionais e nacionais. Isso satisfaz as necessidades de uma grande proporção de consumidores e acaba desencorajando o surgimento de novas iniciativas de produção de alimentos (SCHERMER, 2015). Nesse caso, verifica-se que um há quadro de mudanças que progride para relações consumidor-produtor em resposta a processos mais amplos de transformação social e política (SCHERMER, 2015).

Especificamente na cadeia de suprimento de frutas frescas, sabe-se que ela se caracteriza por obter longos prazos de fornecimento, combinados com 
incertezas significativas de oferta e demanda, que possuem margens relativamente finas (SOTO SILVA et al., 2016). Há também evidências empíricas de estudos realizados no Reino Unido que revelam três características recorrentes na gestão de cadeias de alimentos frescos: a variabilidade na demanda no consumidor, a existência de desalinhamento na demanda e suprimento e a má gestão diária nas atividades ao longo da cadeia (TAYLOR; FEARNE, 2009). Tais desafios geram uma necessidade de eficiência em termos de governança nas cadeias de suprimentos, que podem ser auxiliadas pelo uso de ferramentas modernas de tecnologia de decisão, exigindo a utilização de abordagens holísticas para o projeto e o gerenciamento destas cadeias (SOTO SILVA et al., 2016).

Para entender a complexidade contida nas cadeias produtivas dentro do SAG, cabe salientar que as configurações espaciais são moldadas pelas atividades que caracterizam a cadeia de suprimentos e influenciadas pelo grau em que elas são localizadas (BRUNORI et al., 2016). Assim, o espectro de configurações espaciais analisadas através dos estudos de caso mostra uma variedade impressionante, incluindo desde cadeias radicalmente localizadas (produtos processados na fazenda vendidos para consumidores locais) a cadeias radicalmente globalizadas (BRUNORI et al., 2016). Em vez de uma dicotomia entre local e global, verifica-se um contínuo local-global altamente dinâmico, com cadeias intermediárias emergindo como uma resposta às novas oportunidades do sistema alimentar, às vezes com um resultado do mau funcionamento das cadeias existentes (BRUNORI et al, 2016). Procurando compreender a diversidade de formas de abastecimento de HF, o item 2.1 aborda os canais de comercialização e tipos de mercado que serão estudados no caso empírico.

\subsection{Canais de comercialização e tipos de mercados}

Para analisar as configurações de uma cadeia, um aspecto particularmente desafiador é a definição da unidade de análise e as ferramentas metodológicas disponíveis. No caso deste estudo, o estabelecimento produtor HFé visto como um elo pertencente a um conjunto maior, representado pela cadeia produtiva de HF(NEVES et al., 2017). A dimensão do SAG nos HF apresenta uma complexidade que a diferencia em relação a outros produtos: a natureza biológica da matériaprima (que pode já configurar o produto final), a dependência das condições edafoclimáticas para a produção, a perecibilidade, os aspectos sanitários da produção, a importância para a saúde pública e a dimensão simbólica do consumo dos alimentos, a regulamentação e a intervenção do Estado (MELO, VILELA, 2007; WILKINSON, 2008).

Zybersztajn (2000), ao defender a noção de cadeia produtiva como ferramenta de análise descritiva de um SAG, elenca os principais elementos de análise: os agentes, as relações entre os elos, os setores, as organizações de apoio e o ambiente institucional. Nesse sentido, a identificação do produto final é tomada como objeto de estudo com o encadeamento, a jusante e a montante, e as operações técnicas, comerciais e logísticas necessárias para a produção (BATALHA, 1997).

O foco deste estudo é a análise de como o produtor se posiciona dentro da referida cadeia para comercializar seus produtos. Desse modo, cabe entender o 
caminho percorrido desde a produção até chegar ao consumidor final, o que é representado pelos canais de comercialização. Os canais são caracterizados pelo número de integrantes, os quais incidem no seu comprimento e podem constituir tanto canais diretos como indiretos, conforme existência ou não de intermediários nas relações que os produtores rurais estabelecem com o mercado (SPROSSER; LIMA FILHO, 2007). O número de níveis entre o produtor e o consumidor final define a extensão do canal, o que pode ser classificado conforme propõe Kotler (1998; 2006), representado pelo Quadro 1. A adoção de um canal em detrimento de outro depende de vários elementos, incluindo fatores como eficiência, disponibilidade de mão de obra e grau de especialização, dentre outros fatores (KOTLER, 2006).

Quadro 1. Níveis dos canais de comercialização segundo a classificação proposta por Kotler

\begin{tabular}{|c|c|c|}
\hline Tipo de canal & Definição & Exemplos \\
\hline Canal de nível zero & $\begin{array}{c}\text { Produtor que vende } \\
\text { diretamente ao consumidor } \\
\text { final. }\end{array}$ & $\begin{array}{l}\text { Feiras livres, vendas diretamente } \\
\text { nas residências, cooperativa de } \\
\text { consumidores, lojas próprias de } \\
\text { cooperativas ou associações de } \\
\text { produtores. }\end{array}$ \\
\hline Canal de um nível & $\begin{array}{c}\text { Canal que possui um } \\
\text { intermediário (varejista) na } \\
\text { comercialização dos produtos } \\
\text { agrícolas. }\end{array}$ & $\begin{array}{c}\text { Supermercados, lojas de } \\
\text { conveniência, fruteiras e } \\
\text { açougues. }\end{array}$ \\
\hline $\begin{array}{l}\text { Canal de dois } \\
\text { níveis }\end{array}$ & $\begin{array}{l}\text { Canal que possui dois } \\
\text { intermediários (atacadistas e } \\
\text { varejistas) na comercialização } \\
\text { dos produtos agrícolas. }\end{array}$ & $\begin{array}{l}\text { Centrais de distribuição, } \\
\text { atacados, restaurantes, cozinhas } \\
\text { industriais. }\end{array}$ \\
\hline $\begin{array}{l}\text { Canal de três } \\
\text { níveis }\end{array}$ & $\begin{array}{l}\text { Canal que possui três } \\
\text { intermediários (processadora de } \\
\text { alimentos, atacadista e } \\
\text { varejista) na comercialização } \\
\text { dos produtos agrícolas. }\end{array}$ & $\begin{array}{l}\text { Packinghouse, agroindústrias em } \\
\text { geral, cooperativas } \\
\text { agropecuárias. }\end{array}$ \\
\hline $\begin{array}{c}\text { Canal de quatro } \\
\text { níveis }\end{array}$ & $\begin{array}{l}\text { Canal que possui pelo menos } \\
\text { quatro intermediários }\end{array}$ & $\begin{array}{l}\text { Trading de exportação, centrais } \\
\text { de abastecimento. }\end{array}$ \\
\hline
\end{tabular}

Fonte: adaptado de Kotler $(2006,1998)$.

A escolha dos canais de comercialização mais adequados depende de uma série de fatores, entre os quais destaca-se: i) a natureza e as características do produto, tais como a perecibilidade; ii) a existência ou não de intermediários; iii) o resultado econômico de todo o processo envolvido na cadeia produtiva (WAQUIL; MIELE; SCHULTZ, 2010).O comprimento de um canal de comercialização pode ser ainda o resultado da diversidade de comportamento dos consumidores, das particularidades inerentes à distribuição dos produtos perecíveis e do desejo de otimização do processo de distribuição, especialmente do elo coordenador, podendo ser representado pelo atacado ou varejo, por exemplo (SPROESSER; LIMA FILHO,2007). Tais elementos podem agir de forma a tencionar os produtores a eleger um canal em detrimento de outro, não necessariamente levando-os a uma 
escolha. Além disso, abonam a existência de um número razoável de arranjos organizacionais (SPROESSER; LIMA FILHO,2007).

Nesse sentido, é pertinente considerar na análise da forma de inserção dos agricultores e seus objetivos em relação à produção (PLOEG, 2006). Assim, um agricultor pode possuir apenas produção doméstica (PD)ou, quando o objetivo estiver além do auto abastecimento, os chamados produtores de mercadorias podem ser enquadrados em três categorias, que consideram o grau de mercantilização observada quanto aos recursos usados na produção, a força de trabalho empregada e os objetivos finais da atividade. Dessa forma, tem-se o primeiro tipo, Pequeno Produtor de Mercadorias (PPM), que só tem relações mercantis na venda de sua produção e objetiva a sobrevivência. O segundo tipo é o Produtor Simples de Mercadorias (PSM), que atua visando renda e tem produção e obtenção de recursos no mercado. A última categoria é o Produtor Capitalista de Mercadorias (PCM), o qual trata a sua produção, os recursos e a força de trabalho como mercadorias, tendo como objetivo a mais-valia. Por não tratarem a força de trabalho como mercadoria, pode-se dizer que o PPM e o PSM podem ser vistos como as formas de representação da agricultura familiar nesta proposta de categorização (PLOEG, 2006). Considera-se que, ao diminuir a autonomia, aumentase a dependência externa dos estabelecimentos na medida em que se avança da PSM em direção a PCM, ou seja, conforme o grau de mercantilização é aumentado. Resultam, assim, diferenças nos mercados e consequentemente nos canais de comercialização que estão inseridos. (SCHNEIDER, 2016).

Considerando o trabalho de Ploeg (2006), em que o autor estabelece uma distinção entre os produtores, Schneider (2016) avança no sentido de categorizar os mercados, estabelecendo uma classificação.

A primeira compreende os Mercados de proximidade (MP), que apresentam restrições quanto ao alcance espacial e estão bastante ligados ao contexto local. Além disso, verifica-se uma imersão das trocas em relações sociais de reciprocidade e interconhecimento, de forma que a confiança e amizade dominam a regulação das relações sociais estabelecidas. Os tipos de produtores desta categoria apresentam pouco desenvolvimento de relações mercantis, sendo eles os camponeses e produtores de excedentes (SCHNEIDER, 2016).

A segunda categoria corresponde aos Mercados locais e territoriais (MLT), de importância regional, com uma abrangência espacial para além do local e possui mais identificação com a realidade dos PSM. No MLT, verifica-se uma regulação dividida entre confiança e reputação, aliadas à procedência dos produtos e seu preço. Verifica-se um aumento considerável da mercantilização das relações ao mesmo tempo em que são preservados alguns aspectos do MP, especialmente a imersão em um contexto territorial e social (SCHNEIDER, 2016).

Os Mercados convencionais (MC) são a terceira categoria, em que a mercantilização é dominante. Suas relações têm natureza concorrencial e são pautadas no preço e estabelecimento de contratos, além de que o alcance espacial não se limita ao contexto local e regional, de forma que os produtos ou mercadorias não têm conexão com algum local específico e têm alcance estadual e nacional (SCHNEIDER, 2016). No MC, verifica-se o suprimento por produtores de mercadorias, com destaque para os PCM. 
Por fim, a quarta e última categoria é a de Mercados Públicos e Institucionais (MPI), que na última década ganharam notoriedade para a agricultura familiar. $\mathrm{O}$ MPI é alicerçado nas relações sociais, políticas e mercantis, cujas relações e regulação são pautadas em instrumentos legais, como chamadas públicas e legislações, e seu alcance espacial é multivariado.

Cada um desses mercados se caracteriza por tipos de agricultores, alcance espacial e canais de comercialização, conforme sintetizado no quadro a seguir.

Quadro 2. Tipos de mercados, agricultores, alcance espacial e canais de comercialização

\begin{tabular}{|l|l|l|l|}
\hline Tipo de Mercado & Tipo de Agricultor & $\begin{array}{l}\text { Locus e/ou } \\
\text { alcance } \\
\text { espacial }\end{array}$ & Canais de comercialização \\
\hline $\begin{array}{l}\text { Mercados de } \\
\text { proximidade }\end{array}$ & $\begin{array}{l}\text { Camponês; } \\
\text { Produtor de } \\
\text { excedentes }\end{array}$ & $\begin{array}{l}\text { Spot; } \\
\text { Venda direta; } \\
\text { Somente local }\end{array}$ & $\begin{array}{l}\text { - Na propriedade; } \\
\text { - No domicílio/casa; } \\
\text { - - Entra estrada; } \\
\text { - Feira local; }\end{array}$ \\
\hline $\begin{array}{l}\text { Mercados locais e } \\
\text { territoriais }\end{array}$ & $\begin{array}{l}\text { Agricultor familiar; } \\
\text { Produtor simples } \\
\text { de mercadorias }\end{array}$ & $\begin{array}{l}\text { Spot; } \\
\text { Local, regional } \\
\text { e territorial }\end{array}$ & $\begin{array}{l}\text { - Feira regional e/ou } \\
\text { nacional, eventos; }\end{array}$ \\
- Redes de venda; \\
- Restaurantes; \\
- Associação vendas; \\
- Sacolão
\end{tabular}

Fonte: Adaptado de Schneider (2016).

Considerando que os mercados podem se constituir em mecanismos de inserção social e econômica, podendo resultar no fortalecimento da autonomia dos produtores frente às vulnerabilidades enfrentadas (CONTERATO et al., 2011), este trabalho se reveste de importância para a compreensão dos mercados agroalimentares da agricultura familiar. Dessa forma, busca-se preencher uma lacuna entre as proposições teóricas de mercados agroalimentares (SCHNEIDER, 2016) e a disponibilidade de dados empíricos. Foi definido um subconjunto de fatores produtivos, econômicos e comerciais para qualificar as decisões ou "imposições" pela adoção de diferentes canais de comercialização que, em algum grau, delineiam os mercados acessados. A próxima seção apresenta os passos metodológicos para a realização do trabalho. 


\section{METODOLOGIA}

O objeto deste estudo se concentra no destino dado à produção de hortifrúti na região Central do Rio Grande do Sul (município de Santa Maria) durante os anos de 2016, 2017 e 2018, considerando como unidade de análise o produtor de HF. Para pesquisa de campo, foram realizadas91 entrevistas ${ }^{1}$ semiestruturadas, representando o universo de $100 \%$ dos produtores que estão inseridos nos mercados, identificados a partir dos canais de comercialização em que participam.

O questionário utilizado possuiu quatro seções principais. A primeira buscou caracterizar o "núcleo familiar" por meio de informações a respeito dos integrantes do estabelecimento rural, como relações de parentesco, sexo, idade, escolaridade e ocupação de cada um deles. A segunda parte abordou o "estabelecimento" quanto à sua área e condição de posse, mão de obra utilizada, motivações para atuar na fruticultura/olericultura e organizações ou agentes que serviam de referência ou apoio para exercer a atividade. A terceira parte considerou o "nível tecnológico" do sistema de produção, como formas de cultivo, tipo de pulverizador e tração, formas de adubação, presença ou não de irrigação, presença ou não de plasticultura, fonte de água, métodos de controle de pragas e doenças, principais problemas tecnológicos, etc. Por fim, a quarta parte do questionário abordou a "produção e comercialização", em que se devia registraras espécies cultivadas, idade dos pomares, área, número de safras realizadas anualmente, volume produzido, percepção do produtor sobre sua produção - considerando se era suficiente para a demanda de mercado e se havia intenção de aumentar a produção de alguma espécie. Após aplicação do questionário, foi registrada a representatividade de cada canal de comercialização adotado.

Os dados foram digitados e tabulados em um banco de dados pertencente ao Grupo Interdisciplinar de Pesquisas Agroalimentares (GIPAG) e ponderados qualitativamente. $\mathrm{Na}$ análise, os agricultores foram tipificados de acordo com o número de canais de comercialização utilizados (KOTLER, 2006), com suas lógicas sócio-econômico-produtivas (PLOEG, 2006) e conforme os mercados adotados (SCHNEIDER, 2016). Daí que deriva-se os principais resultados, os quais serão apresentados a seguir.

\section{RESULTADOS E DISCUSSÃO}

O entendimento das particularidades dos canais de comercialização é relevante, já que, juntamente com o alcance espacial dos mercados e a classificação dos produtores, é a base para a categorização de mercados. Assim, esta seção apresenta primeiramente a configuração e a representatividade dos canais verificados na pesquisa. A seguir, busca-se emoldurar o elo produtivo conforme suas características para, então, analisar os dados coletados frente à classificação dos mercados.

\footnotetext{
${ }^{1}$ Para aplicação dos questionários, contou-se com a colaboração e apoio de colegas e pesquisadores parceiros que integram o Departamento de Educação Agrícola e Extensão Rural, e do Colégio Politécnico da Universidade Federal de Santa Maria.
} 


\subsection{Canais de comercialização}

Os canais adotados pelos produtores para venda de hortifrúti foram oito, quais sejam: Feiras; Venda Direta no estabelecimento; Entregas à domicílio; Vendas em Restaurantes; Venda em pequeno comércio local; Entrega dos produtos em Cooperativa; Venda a Distribuidores e comercialização em Supermercados. Adotouse o critério de que o produtor poderia direcionar toda a produção apenas para um desses canais ou utilizar concomitantemente quantos julgasse necessário. Assim, 45 produtores (49\%) afirmaram utilizar apenas um canal de comercialização, 29 (32\%) utilizam pelo menos dois canais, 15 (16\%) adotam três canais e apenas 2 (2\%) adotam quatro canais de comercialização, conforme pode ser visualizado no Gráfico 1.

Gráfico 1. Número de canais de comercialização acessados pelos produtores de hortifrúti de Santa Maria/RS

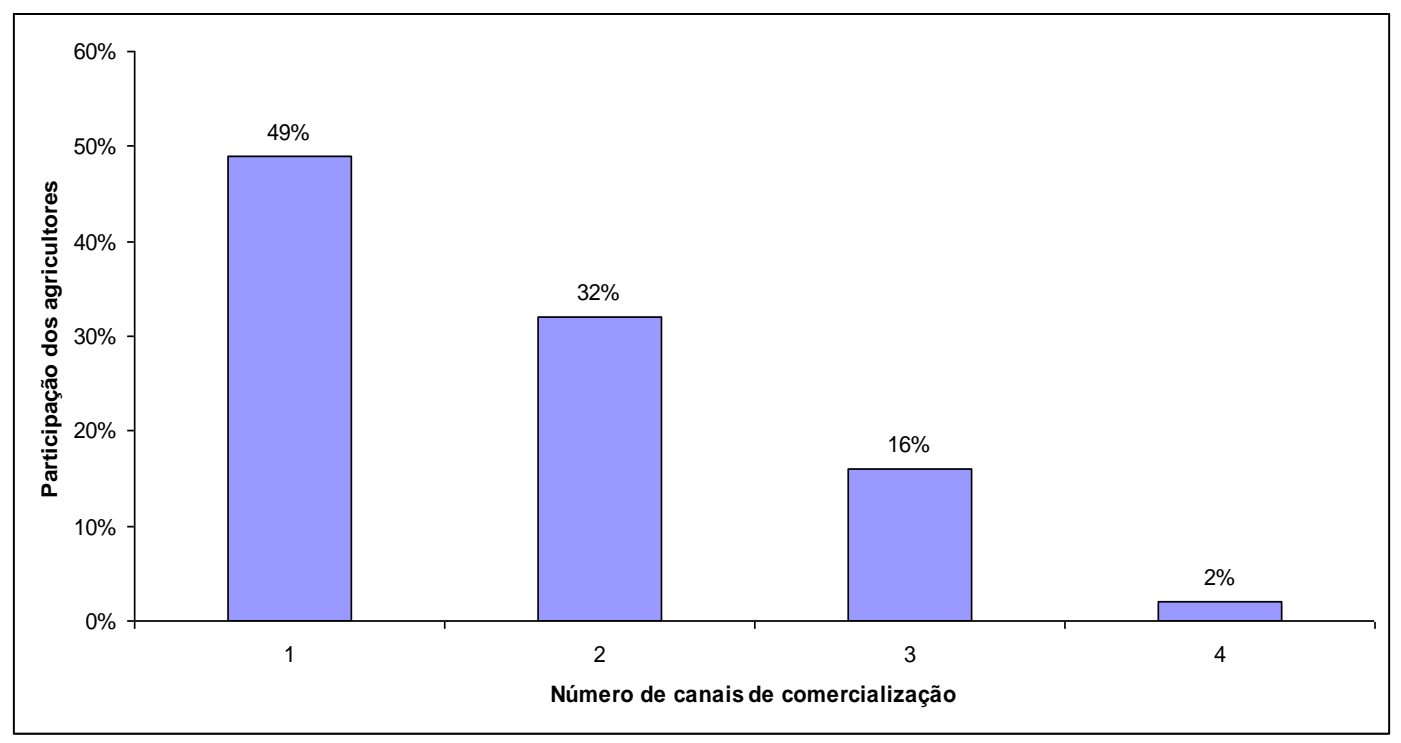

Fonte: Pesquisa de campo, 2018.

Aproximadamente metade dos produtores opta por utilizar exclusivamente um canal de comercialização (49\%) e o máximo de canais adotados concomitantemente pelos produtores é quatro de um total de oito canais disponíveis (verificados empiricamente na pesquisa).

Chama atenção o alto número de agricultores que utiliza apenas um canal de comercialização. Isso por que, guardada a particularidade da comercialização de orgânicos, tem-se que, produtores de hortifrúti possuem como estratégia, na maioria dos casos, a participação em mais de um canal de comercialização (SCHULTZ, SOUZA JANDREY, 2017). A pesquisa realizada por Schultz, Souza Jandrey (2017) mostrou que entre os fornecedores de hortaliças orgânicas da Serra do RS, apenas $29 \%$ dos produtores acessavam somente um canal, $39 \%$ acessavam dois canais, $20 \%$ três canais e $12 \%$ quatro canais de comercialização (SCHULTZ, SOUZA JANDREY, 2017).

Dentre os canais encontrados em Santa Maria, a Feira ocupou posição de destaque - já que conta com a participação de $72,5 \%$ dos produtores de hortifrúti -, seguido pelo supermercado, com $26,4 \%$ dos produtores, conforme demonstra o 
Gráfico 2. Em seguida, há a Cooperativa com 19,8\%, na sequência as vendas realizadas diretamente nos estabelecimentos rurais, com $17,6 \%$, o pequeno comércio local com $11 \%$ e, por fim, os restaurantes com $0,66 \%$ e distribuidores com $0,22 \%^{2}$.

Gráfico 2. Acesso dos agricultores aos canais de comercialização

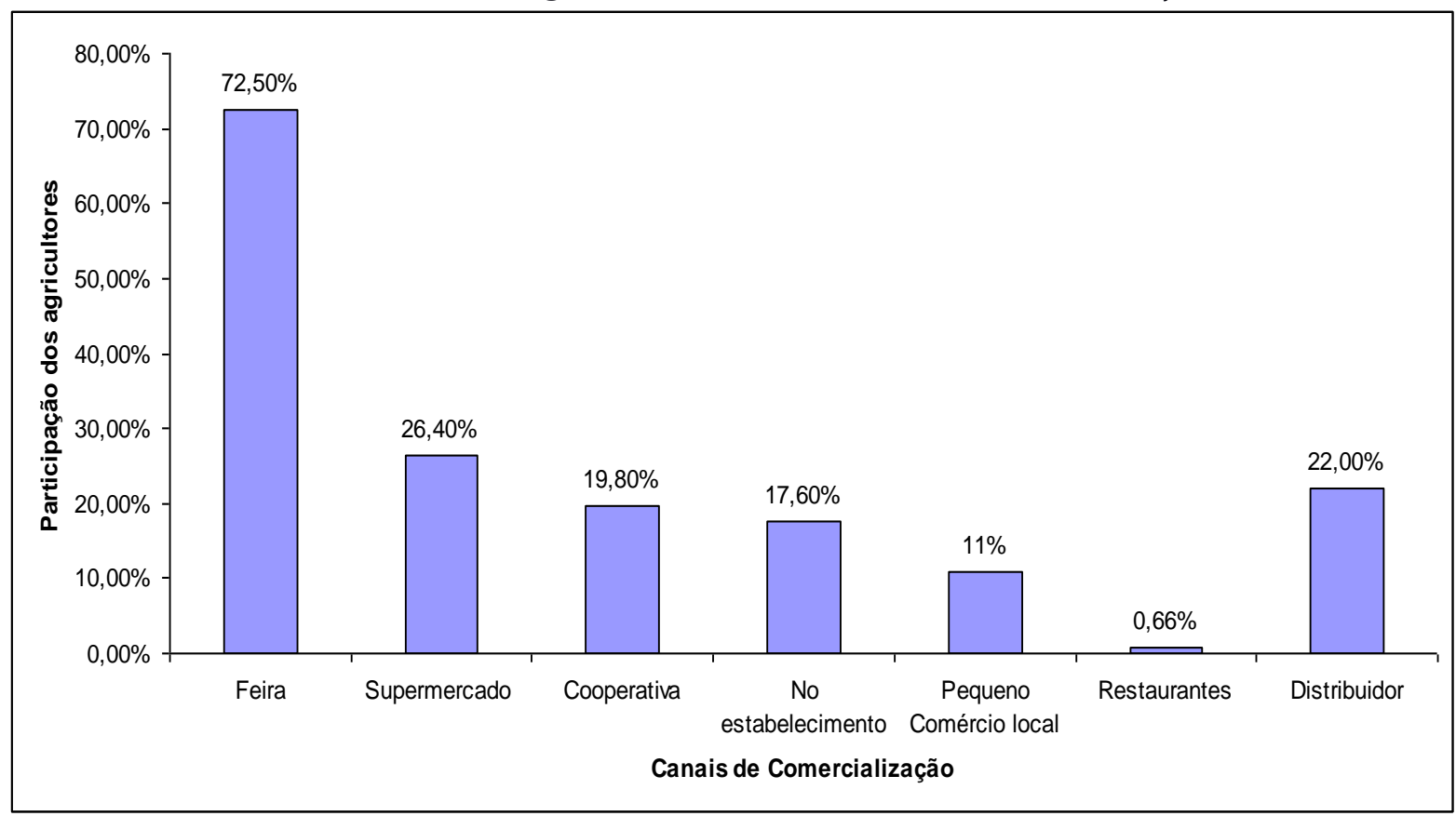

Fonte: Pesquisa de campo, 2018.

A feira é o canal mais acessado pelos produtores de hortifrúti de Santa Maria. Em relação aos agricultores que vendem produtos orgânicos na região da Serra do Rio Grande do Sul, 80\% dos agricultores acessam supermercados, $78 \%$ as feiras, $35 \%$ os mercados institucionais, $20 \%$ as lojas especializadas e $4 \%$ também comercializam na propriedade (SCHULTZ; SOUZA; JANDREY, 2017).

O Gráfico 3 apresenta a participação dos agricultores de acordo com a classificação dos canais proposta por Kotler (1998), que observa principalmente o número de intermediários entre o elo da produção e o consumidor final. Foram verificados quatro tipos de canais de comercialização. O destaque foi o Canal de Nível Zero, ou seja, quando o produtor vende diretamente ao consumidor final, representado neste caso pelas feiras livres e vendas diretamente nas residências. Em segundo lugar, por ordem de importância, tem-se o Canal de Um Nível, que apresenta um intermediário (varejista) na comercialização dos produtos agrícolas, constituído neste estudo especialmente pela presença de supermercados e comércio local. O Canal de Três Níveis ocupa a terceira posição e é caracterizado por possuir três intermediários na comercialização dos produtos agrícolas (incluindo mais um elo, que é a cooperativa). Com apenas $1 \%$ de representatividade, tem-se o Canal de Dois Níveis, que possui pelo menos dois intermediários entre o produtor e

\footnotetext{
${ }^{2}$ A soma dos canais é superior a $100 \%$ justamente porque $51 \%$ dos produtores utilizam concomitantemente mais de um canal de comercialização.
} 
consumidor final (neste estudo, constituído por uma central de distribuição ou o elo restaurante).

Gráfico 3. Representatividade dos canais de comercialização conforme os níveis



Fonte: Pesquisa de Campo, 2018.

O Gráfico 3 expõe a relevância dos canais de nível zero, especialmente o caso das feiras, utilizada como principal canal de comercialização e corroborando os dados encontrados por Ojima e Silva (2005). O único canal não acessado pelos agricultores é o canal de quatro níveis, que possui como característica pelo menos quatro intermediários até o consumidor final (que poderia ser representado por uma central de abastecimento). O fato de não haver, na região, a participação dos agricultores neste canal é de fácil compreensão. Primeiro, por não existir uma Central de Abastecimento do Rio Grande do Sul (CEASA) na região. Segundo, por não haver quantidade suficiente de produção que justifique o envio de excedentes para Porto Alegre, onde se localiza a CEASA/RS.

A predominância na adoção dos canais mais curtos de comercialização (se somados canal de nível zero e canal de nível um, obtêm-se $86 \%$ das transações realizadas) pode ser explicada, neste caso, por pelo menos três fatores: i) a maior parte dos produtores pesquisados possui uma escala de produção pequena se comparado com produtores patronais, o que inviabilizaria transações com redes varejistas (BRANDÃO; ARBAGE, 2016); ii) geograficamente o município se localiza cerca de $300 \mathrm{~km}$ da CEASA-RS, o que dificultaria o transporte até o grande centro distribuidor; iii) trata-se, na maioria dos casos, de produtos com alta perecibilidade, o que exige um arranjo de canal de distribuição que permita uma comercialização mais eficiente e ágil. Muitas vezes essa agilidade está fora do alcance dos produtores, forçando-os a limitar suas vendas ao contexto local e/ou regional (LOURENZANI; SILVA, 2004).

Embora estudos comprovem que a capacidade de acessar o mercado é muitas vezes limitada e constitui uma das principais restrições à melhoria dos meios de subsistência da agricultura familiar em muitos países em desenvolvimento (SWENSSON, 2019) esperava-se uma maior diversidade de canais de comercialização, 
uma vez que, como referendam Conterato et al. (2011), o maior número de canais é uma explicação para a permanência e para o fortalecimento da agricultura familiar em ambientes econômicos e sociais onde acontecem suas relações de troca.

Porém, cabe ponderar que, quanto maior número de níveis do canal de comercialização, mais complexas serão as transações e, por consequência, as relações estabelecidas ao longo do canal. Entre os aspectos relacionais, os entrevistados citam como determinantes na escolha dos canais a "acessibilidade", representada pela inexistência de barreiras, a entrada, a confiança e a segurança através da garantia da venda do produto (ou seja, menor incerteza).

\subsection{Tipos de Produtores e Tipos de Mercados para Hortifrútis}

Para entender as escolhas dos agricultores, é relevante compreender sua lógica sócio- econômica-produtiva. Para tanto, o elo da produção foi segmentado conforme a perspectiva teórica sugerida por Ploeg (2006), focando nos aspectos da força de trabalho empregada e nos objetivos finais da atividade ${ }^{3}$. O PPM se trata do agricultor familiar que não contrata assistência técnica e/ou mão de obra para a produção, que utiliza das relações mercantis apenas na venda de sua produção e objetiva a reprodução familiar. Ou seja, na noção de cadeia apenas a montante possui relações mercantis. Já o PSM possui uma visão focada na renda, podendo possuir aporte técnico e creditício, sem necessariamente contratar mão de obra, além de possuir relações mercantis à jusante e a montante na cadeia. Por fim, o PCM tem os elementos à jusante e à montante como mercadoria. Em resumo, esta categorização tem a ver com os graus de mercantilização, e não apenas com o tipo de uso da Força de Trabalho (FT). O PPM vende basicamente os excedentes da produção, não produzindo de forma especializada tampouco em grande volume; já o PSM é um produtor que estrutura o processo produtivo para a venda, sendo, em geral, especializado em poucos produtos. Por fim, o PCM é quem produz exclusivamente para vender, utilizando FT contratada.

Com base nesses critérios, constatou-se nesta pesquisa que 50,5\% (46 produtores) podem ser caracterizados como PPM, 39,5\% como PSM (36 produtores) e $11 \%$ como PCM (10 produtores). PD não foram encontrados, pois, conforme explicado na metodologia, foram selecionados somente produtores que apresentavam atividade de produção com o fim comercial. Constatou-se que, dentre os PPM, todos os agricultores participam de canais de comercialização de nível zero. Já na categoria PSM, verifica-se a participação em canais de nível zero, um nível e dois níveis. Em meio aos PCM, têm-se a participação dos agricultores nos canais de um nível e três níveis. Decorre disso duas conclusões: para uma mesma categoria de classificação de agricultores, pode-se verificar a utilização de

\footnotetext{
${ }^{3}$ Considera-se um limitante o fato da pesquisa não abranger mais profundamente os recursos usados na produção para auxiliar no enquadramento dos produtores na classificação de Ploeg (2006). Entretanto, para classificar em PPM, PSM ou PCM foram considerados os outros dois aspectos estabelecidos pelo autor: força de trabalho empregada e os objetivos finais da atividade. A justificativa para esta limitação é que o presente estudo se baseia nos aspectos à jusante da cadeia, ou seja, a comercialização.
} 
diferentes canais de comercialização; existe uma conexão entre o tipo PPM e a utilização de canais de nível zero.

Considerando a realidade brasileira, sugere-se uma adequação à tipologia proposta por Ploeg (2006). Os PD, PPM, PSM estão baseados no uso de FT da família, portanto, são agricultores familiares. O PCM é baseado em trabalho contratado. No Brasil como um todo, teríamos ainda um quinto tipo de produtor rural, que é o Produtor Rentista (PR), aquele grande proprietário que vive de arrendar suas terras e ganha parte da produção dos arrendatários para se manter. Como exemplos de PR, há os típicos casos dos coronéis do Nordeste (SILVA, 2017), os arrendatários de terra na Fronteira Oeste do RS (BRANDÃO; ANVERSA; DREBES, 2017) e os grandes proprietários de terras da Amazônia do Brasil (PEREIRA, 2016).

Quanto à classificação dos mercados no contexto de Santa Maria, constatouse que não foi possível encontrar "tipos puros", propostos por Schneider (2016). Ou seja, unidades que vendem apenas para um canal e contemplem todas as características propostas, que acessem ou participem apenas de um mercado, por exemplo. O Quadro 3 ilustra em que medida as características propostas na teoria encontraram correspondência no ambiente empírico estudado.

Quadro 3. Enquadramento da Realidade empírica dos Mercados de Hortifrúti de Santa Maria na Tipologia dos mercados da Agricultura Familiar de Schneider (2016)

\begin{tabular}{|c|c|c|c|}
\hline $\begin{array}{l}\text { Tipo de } \\
\text { Mercado }\end{array}$ & Característica & Observação de campo & $\begin{array}{c}\text { Conformidade } \\
\text { com a teoria }\end{array}$ \\
\hline \multirow{4}{*}{$\begin{array}{l}\text { Mercados de } \\
\text { Proximidade } \\
\qquad(M P)\end{array}$} & Lócus ou alcance espacial & Alcance espacial local & $\checkmark$ \\
\hline & Base de Relacionamento & $\begin{array}{l}\text { Reciprocidade e } \\
\text { confiança }\end{array}$ & $\checkmark$ \\
\hline & Tipo de produtor & Produtor de excedentes & $x$ \\
\hline & Canais de comercialização & Nível Zero & $\checkmark$ \\
\hline \multirow{4}{*}{$\begin{array}{l}\text { Mercados } \\
\text { Locais e } \\
\text { Territoriais } \\
\text { (MLT) }\end{array}$} & Lócus & $\begin{array}{l}\text { Alcance para além do } \\
\text { local }\end{array}$ & $x$ \\
\hline & Relacionamento & $\begin{array}{l}\text { Reciprocidade e } \\
\text { confiança aliada a preço }\end{array}$ & $\checkmark$ \\
\hline & Tipo de produtor & Produtor familiar; PSM & $\checkmark$ \\
\hline & Canais de comercialização & Um e dois Níveis & $\checkmark$ \\
\hline \multirow{4}{*}{$\begin{array}{c}\text { Mercados } \\
\text { Convencionais } \\
\text { (MC) }\end{array}$} & Lócus & Rompe contexto local & $x$ \\
\hline & Relacionamento & Concorrenciais & $\checkmark$ \\
\hline & Tipo de produtor & PCM & $\checkmark$ \\
\hline & Canais de comercialização & Um, Dois e Três Níveis & $\checkmark$ \\
\hline
\end{tabular}

Fonte: Pesquisa de campo, 2018.

As diferenças encontradas entre os tipos ideais e a realidade no campo são previstas na teoria utilizada. Todavia, a hipótese contida na tipologia dos mercados da agricultura familiar de Schneider (2016) pressupõe que os agricultores participem de uma heterogeneidade de canais de comercialização, e considera que, quanto mais diversos são/forem estes outlets acessados, maior será sua autonomia porque sua dependência seria menor. O Quadro 3 evidenciou as características do ambiente empírico, cujas particularidades serão discutidas a seguir. 
No Mercado de Proximidade, a divergência com a tipologia de Schneider (2016) está relacionada ao tipo de produtor participante. O perfil do produtor encontrado é muito mais relacionado ao Agricultor Familiar ou PSM do que apenas um Produtor de Excedentes. Isso é evidente para os autores porque, por ora da seleção, foram eleitos apenas agricultores que produziam com fins comerciais, e não aqueles que apenas vendiam o excedente (embora nada impeça que, ocasionalmente, um agricultor leve para a feira, por exemplo, algo que era para consumo próprio e excedeu sua demanda).

No caso MLT, os critérios apontados por Schneider (2016) em maior parte também foram corroborados pelos dados encontrados a campo. A ponderação ficaria a cargo do alcance dos produtos, já que o próprio município sede a qual os agricultores pertencem é a referência regional em termos de "centro de demanda". Desse modo, os produtos não se deslocam geograficamente, sendo comercializados dentro do próprio município. Por outro lado, pode-se considerar que há alcance além do local, porque os consumidores vêm de outros municípios para Santa Maria, por se tratar de uma cidade referência em prestação de serviços, saúde e educação. Assim, acabam usufruindo desse tipo de produção de Santa Maria por meio da utilização dos serviços de alimentação.

Nos critérios pertencentes ao MC, foi encontrada divergência apenas no que concerne ao lócus geográfico. Isso porque os produtos que são destinados, por exemplo, aos supermercados ou ao comércio local (empresa privada) são comercializados no âmbito do próprio município, ou seja, não são distribuídos para outra região. Todavia, da mesma forma que no caso anterior, por ser um polo de compras, é possível que os consumidores de outros municípios façam compras em Santa Maria e levem os produtos para outras cidades, até mesmo para comercializar em pequenos mercados locais de outras cidades.

Como a proposição de Schneider (2016) sustenta que os agricultores deveriam participar de uma heterogeneidade de canais de comercialização, considerando que quanto mais diversos forem estes outlets acessados maior será sua autonomia, a relevância não está atrelada apenas a percentagem de vendas para um ou outro canal, mas, especialmente, a heterogeneidade de canais que o produtor/vendedor tem à sua disposição como uma possibilidade. A explicação teórica centra-se no fato de que a classificação dos produtores, a partir da percentagem que destinam a cada canal, implicará na classificação do mercado que ele utiliza. Por exemplo, se um produtor destina a parcela maior das vendas para a Feira, ele será classificado como MP. Tais informações estão sistematizadas no Quadro 4. 
Quadro 4. Número de Canais, mercados e percentual correspondente de participação da produção no canal de correspondente

\begin{tabular}{|c|c|c|c|c|c|c|c|}
\hline \multirow{2}{*}{$\begin{array}{c}\text { Número de } \\
\text { canais } \\
\text { adotados/ } \\
\text { Participação } \\
\text { dos } \\
\text { agricultores }\end{array}$} & \multirow{2}{*}{$\begin{array}{c}\text { Tipo de } \\
\text { mercado/\% } \\
\text { de } \\
\text { agricultore } \\
\text { s que o } \\
\text { utilizam }\end{array}$} & \multirow[b]{2}{*}{ Canal } & \multicolumn{5}{|c|}{$\begin{array}{c}\text { Percentual da produção total } \\
\text { direcionada ao canal }\end{array}$} \\
\hline & & & $100 \%$ & $\begin{array}{c}100 \%- \\
80 \%\end{array}$ & $\begin{array}{l}80 \%- \\
50 \%\end{array}$ & $\begin{array}{l}50 \%- \\
20 \%\end{array}$ & $\begin{array}{c}20 \%- \\
0 \%\end{array}$ \\
\hline \multirow{7}{*}{$\begin{array}{c}1 \\
49 \%\end{array}$} & \multirow{3}{*}{$\begin{array}{l}M P \\
80 \%\end{array}$} & $\begin{array}{c}\text { Vendas no } \\
\text { estabelecimento }\end{array}$ & 6 & - & - & - & - \\
\hline & & Entrega domiciliar & 1 & - & - & - & - \\
\hline & & Feiras & 29 & - & - & - & - \\
\hline & \multirow{3}{*}{$\begin{array}{l}\text { MLT } \\
13,3 \%\end{array}$} & Restaurantes & 1 & - & - & - & - \\
\hline & & $\begin{array}{l}\text { Peq. e Médio } \\
\text { Comércio }\end{array}$ & 2 & - & - & - & - \\
\hline & & Cooperativa & 3 & - & - & - & - \\
\hline & $\begin{array}{l}M C \\
6,6 \%\end{array}$ & Supermercados & 3 & - & - & - & - \\
\hline \multirow{8}{*}{$\begin{array}{c}2 \\
32 \%\end{array}$} & \multirow{3}{*}{$\begin{array}{l}\text { MP } \\
55 \%\end{array}$} & $\begin{array}{c}\text { Vendas no } \\
\text { estabelecimento }\end{array}$ & - & - & - & - & 5 \\
\hline & & Entrega domiciliar & - & 1 & - & 1 & 1 \\
\hline & & Feiras & - & 13 & 2 & 9 & 3 \\
\hline & \multirow{3}{*}{$\begin{array}{l}\text { MLT } \\
25 \%\end{array}$} & Restaurantes & - & - & - & 3 & 1 \\
\hline & & $\begin{array}{l}\text { Peq. e Médio } \\
\text { Comércio }\end{array}$ & - & - & 1 & 1 & 1 \\
\hline & & Cooperativa & - & 1 & 2 & 2 & 3 \\
\hline & \multirow{2}{*}{$\begin{array}{l}\text { MC } \\
18 \% \\
\end{array}$} & Supermercados & - & 1 & 7 & 1 & 1 \\
\hline & & Distribuidor & - & - & - & 1 & - \\
\hline \multirow{7}{*}{$\begin{array}{c}3 \\
16 \%\end{array}$} & \multirow{3}{*}{$\begin{array}{l}\text { MP } \\
43 \%\end{array}$} & $\begin{array}{c}\text { Venda no } \\
\text { estabelecimento }\end{array}$ & - & - & - & - & 4 \\
\hline & & Entrega domiciliar & - & - & - & 1 & 3 \\
\hline & & Feira & - & 3 & 1 & 3 & 1 \\
\hline & \multirow{2}{*}{$\begin{array}{l}\text { MLT } \\
27 \%\end{array}$} & $\begin{array}{l}\text { Peq. e Médio } \\
\text { Comércio }\end{array}$ & - & - & - & 2 & 2 \\
\hline & & Cooperativa & - & - & 3 & 3 & - \\
\hline & \multirow{2}{*}{$\begin{array}{l}\text { MC } \\
30 \%\end{array}$} & Supermercados & - & 2 & 3 & 2 & 3 \\
\hline & & Distribuidor & - & - & 1 & - & - \\
\hline \multirow{7}{*}{$\begin{array}{c}4 \\
2 \%\end{array}$} & \multirow{3}{*}{$\begin{array}{l}M P \\
50 \%\end{array}$} & $\begin{array}{c}\text { Vendas no } \\
\text { estabelecimento }\end{array}$ & - & - & - & - & 1 \\
\hline & & Entrega domiciliar & - & - & - & 1 & - \\
\hline & & Feiras & - & 1 & - & 1 & - \\
\hline & \multirow{3}{*}{$\begin{array}{l}\text { MLT } \\
37 \%\end{array}$} & Restaurantes & - & - & - & - & 1 \\
\hline & & $\begin{array}{c}\text { Peq. e Médio } \\
\text { Comércio }\end{array}$ & - & - & - & - & 1 \\
\hline & & Cooperativa & - & - & - & 1 & - \\
\hline & $\begin{array}{c}M C \\
12,5 \% \\
\end{array}$ & Supermercados & - & - & - & - & 1 \\
\hline
\end{tabular}

Fonte: Pesquisa de campo, 2018. 
Dentre os $49 \%$ produtores que adotam somente um canal, conforme exposto no Gráfico 4, 80\% foram classificados em MP; 13,3\% em MLT e 6,6\% em MC. No caso dos $32 \%$ de agricultores que adotam dois canais de comercialização, são predominantes as transações em MP: 55,93\%; MLT: 25,42\% e MC: $18,64 \%$. Nos 16\% estabelecimentos envolvidos com três canais há mais equilíbrio entre o número de transações realizadas em cada tipo de mercado, apresentando a seguinte proporção: MP: 43,24\%; MLT: 27,02\%; e MC: $29,72 \%$. Por fim, os $2 \%$ dos estabelecimentos que utilizam quatro canais de comercialização tem MP: $50 \%$; MLT: $37,5 \%$ e MC: $12,5 \%$.

No que se refere ao MP, o destaque é a Feira, com participação de 66 produtores $(72,5 \%)$. Para 29 desses produtores, a feira representa a única forma de venda da produção; para 20 corresponde ao direcionamento de mais de $50 \%$ do total da produção; e para 17 o canal utilizado para a comercialização é de $50 \%$ ou menos (Quadro 4). Com isso, verifica-se a importância deste canal, pois não só tem uma elevada adoção, mas também representa o principal meio de comercialização para pelo menos 49 produtores, que somam $53,8 \%$ do público total investigado. Já a venda direta no estabelecimento é acessada por 16 produtores (17,6\%), sendo o único canal adotado por 6 produtores, enquanto para os demais se trata de um canal que recebe até $20 \%$ do total produzido. Por fim, as vendas com entrega à domicílio são uma opção de 9 produtores (9,9\%), em que dois deles direcionam a este canal mais de $80 \%$ de sua produção, e os demais, até $50 \%$ do total produzido em volume.

Quanto aos MLT, representados pelos restaurantes, pequenos e médios comércios e pela cooperativa, o relacionamento entre agricultores e compradores é orientado tanto por uma dinâmica mercantil como pelo interconhecimento e relações pessoais existentes entre os agentes envolvidos. Ao todo, 6 produtores $(6,6 \%)$ têm os restaurantes como consumidores, em que um produtor direciona $100 \%$, e os outros 5 até $50 \%$ de sua produção para este canal. Os Pequenos e Médios Comércios são atendidos por 10 produtores (11\%), recebendo $100 \%$ dos produtos de dois deles, entre $50 \%$ e $80 \%$ de um, e menos de 50\% dos 7 restantes. Já a Cooperativa conta com 18 produtores que praticam entregas (19,8\%), dos quais 3 direcionam $100 \%$ de seus produtos a este canal, 6 entre 50 e 100\%, e 9 que vendem menos de $50 \%$ da produção utilizando este canal.

Por fim, os MC são representados pelos supermercados e distribuidores de hortifrútis, predominantemente com relação mercantil entre os agentes. Os Supermercados são o segundo canal mais adotado, abarcando 24 produtores (26,4\%), dos quais 3 utilizam somente este canal, 13 direcionam mais de $50 \%$ de sua produção, e 8 menos de $50 \%$. Os distribuidores têm uma atuação limitada, foram verificados apenas 2 produtores (0,22\%) que adotam este canal: em um dos casos, 0 produtor vende de 50 a $80 \%$ de seus produtos a uma empresa especializada em atender licitações públicas para o PAA; enquanto o outro vende de 20 a 50\% de sua produção a um distribuidor, que compartilha frutas e hortaliças com os municípios da Região Sul do Rio Grande do Sul.

Observa-se que o MP é o mercado mais relevante no caso dos produtores de $\mathrm{HF}$, independentemente do número do número de canais acessados. Com isso, verifica-se a importância dos circuitos mais localizados para a comercialização e constituição da renda dos agricultores locais. Esse potencial advém da importância 
do consumo no município de Santa Maria para a região central do estado, já que possui 277.309 mil habitantes (IBGE, 2016). Por fim, os MC abarcam uma menor parte das transações realizadas (18,6\%).

No caso dos agricultores que participam de dois canais ou mais simultaneamente, a observação do percentual dos volumes direcionados em cada canal auxilia na compreensão de por que há um equilíbrio entre a utilização dos diferentes mercados MP, MLT e MC. Há sempre uma predominância dos mercados de proximidade, seguido do local territorial e, por último, do mercado convencional. Em outras palavras, os agricultores diversificam os canais de comercialização, adequando os volumes destinados, o que resulta em uma relação um pouco mais equilibrada da proporção de participação em MP, MLT e MC. O mesmo não acontece quando se analisa os produtores que representam $80 \%$ de MP para os que participam apenas de canais de nível zero, sem intermediários, verificando-se que, devido à participação do agricultor em um único canal, há uma tendência de concentração da comercialização para um tipo mercado.

Destaca-se a situação distinta encontrada no caso dos $80 \%$ que estão em MP e participam apenas de Canais de Nível Zero, sem intermediários. Devido à participação do agricultor em um único canal, há uma tendência de concentração da comercialização para apenas um tipo mercado. Para Conterato et al. (2011), na luta por autonomia os agricultores tendem a incorrer no distanciamento em relação a alguns circuitos de troca, especialmente quando são simplesmente fornecedores de mercadorias.

Não foi verificada nenhuma forma de participação direta dos produtores no MPI, mas estes estão, de certa forma, presentes em função de que esses mercados são abastecidos por meio de uma cooperativa da agricultura familiar citada no MLT. Como a cooperativa também fornece alimentos para outros tipos de mercados (institucional e comercialização direta para os consumidores), os agricultores não souberam informar com precisão qual a destinação da produção 4 .

Posta a distribuição dos canais utilizados, constata-se que não é possível afirmar que a adoção de um canal ou outro é mais ou menos adequada aos produtores de $\mathrm{HF}$, pois dependeria de vários fatores que deveriam ser alvo de estudos futuros(como, por exemplo, custos de transação, estruturas de governança, ambiente organizacional e institucional, etc.). Entretanto, resulta disso a seguinte questão: no caso estudado, os produtores de HF utilizam majoritariamente canais de nível zero por opção ou contingenciamento?

Procurando obter resposta, recorre-se à literatura e ao ambiente empírico, que implicam em uma linha de raciocínio. BRANDÃO e ARBAGE (2016), em pesquisa realizada na mesma região a que se refere esse artigo, constataram que as redes regionais de varejo organizam suas cadeias de suprimentos buscando qualidade, regularidade e volume, o que restringe o acesso dos produtores locais de $\mathrm{HF}$ a $\mathrm{MC}$ especialmente pela regularidade e volume. Por outro lado, percebe-se que, em Santa Maria, o consumidor tem se mostrado receptivo à consolidação de canais

\footnotetext{
${ }^{4}$ O canal de comercialização cooperativa opera como um mercado local e territorial, mas na classificação de Schneider aparece como mercado convencional. Entretanto, é sabido que essa Cooperativa no caso de Santa Maria comercializa com os mercados institucionais.
} 
diretos. Isso pode ser comprovado por toda sorte de estabelecimento de espaços de inserção à mercados de proximidade (Vasile e da Cruz, 2019), tais como feiras regionais, eventos locais e projetos de extensão universitárias bem-sucedidos. Estas evidências sugerem o encurtamento das cadeias (CUNHA, 2016), baseadas em relações diferenciadas entre consumidor-produtor (SCHERMER, 2015), o que corrobora tendências de SAG mais localizados (BRUNORI et al., 2016). Destarte, pondera-se que, no caso estudado, a não recorrência de uma diversidade maior de canais, que resultaria em uma maior autonomia de mercados, é possivelmente explicada por fatores contingenciais e não exatamente por escolha livre e arbitrária do produtor de HF.

A Figura 1resume os dados obtidos, evidenciando as diferentes configurações da comercialização dos hortifrútis produzidos em Santa Maria. Para isso, o elo de referência considerado como unidade de análise da cadeia foi o produtivo, considerando o perfil do produtor, o destino dos produtos e os relacionamentos estabelecidos. De acordo com a perspectiva teórica, a Figura 1compreende três subdivisões: Tipo de Produtor (PLOEG, 2006); Canal de Comercialização (KOTLER, 2006); Tipo de Mercado (SCHNEIDER, 2016).

Figura 1 - Fluxos de comercialização de hortifrútis em Santa Maria/RS

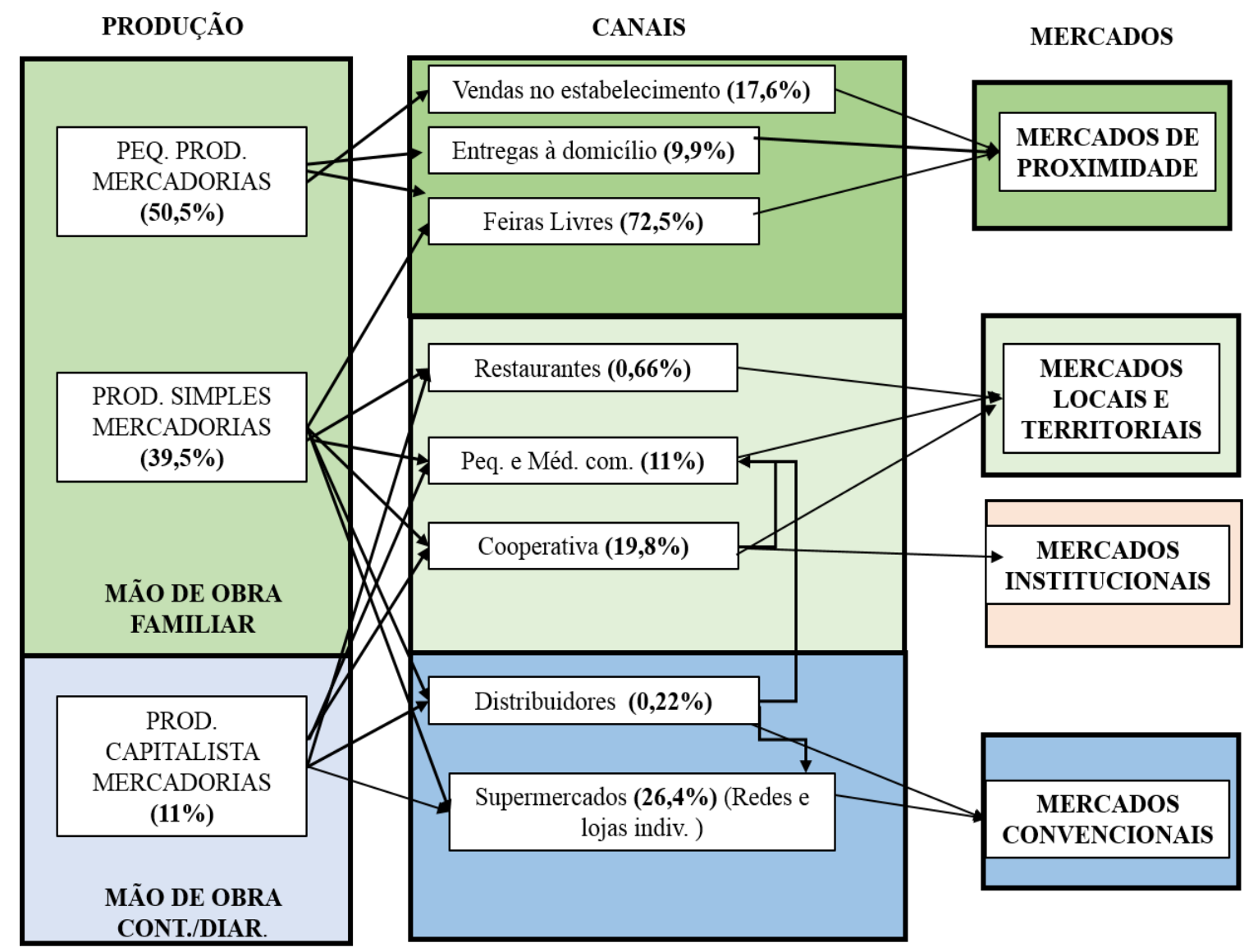

Fonte: pesquisa de campo, 2018. 


\section{CONSIDERAÇÕES FINAIS}

Observou-se a tendência para mercados amparados em canais de nível zero, com o encurtamento da cadeia e destaque para as feiras livres de agricultores, com alcance físico espacial local. Assim, embora haja uma diversidade de canais nos quais os agricultores de HF de Santa Maria/RS se inserem, existe dependência dos mercados de proximidade e territoriais. Isso mostra como a cadeia dos hortifrútis em Santa Maria/RS é localizada, o que demanda estudos futuros para analisar os fatores causais.

Como destaque, ressalta-se que apenas $18 \%$ dos produtores vendem para 3 (16\%) ou 4 (2\%) canais. Ademais, dos $49 \%$ produtores que adotam somente um canal, pelo menos $80 \%$ foram classificados em MP. Isso significa que os MP também podem se caracterizar por um número reduzido de canais de venda. Como a hipótese de Schneider (2016) sustentava que os agricultores deveriam participar de uma heterogeneidade de canais de comercialização, considerando que, quanto mais diversos forem estes outlets acessados maior seria sua autonomia, a relevância não está atrelada apenas a percentagem de vendas para um ou outro canal, mas especialmente a heterogeneidade de canais que o produtor/vendedor tem à sua disposição como uma possibilidade. A explicação teórica centra-se no fato de que a classificação dos produtores a partir da percentagem que destinam a cada canal implicará na classificação do mercado que ele utiliza. Por exemplo, se um produtor destina a parcela maior de suas vendas para a Feira, ele será classificado como MP. Isso significa que, provavelmente, a autonomia não advém apenas do fato de um produtor acessar vários canais (ou níveis), mas deve-se considerar o controle ou governança sobre aqueles em que atua, como é o caso do canal de venda direta na Feira. Ademais, há que se considerar também que um agricultor pode participar de diversos pontos de venda dentro de um mesmo canal de comercialização.

Tanto a classificação de Kotler $(1998,2006)$, Ploeg (2006) como a classificação proposta por Schneider (2016) se mostraram proveitosas para o entendimento dos mercados agroalimentares para a cadeia de HF. As divergências encontradas são inerentes a qualquer teoria que seja confrontada com a complexidade de um ambiente empírico. Todavia, sugere-se a inserção de um novo tipo na categorização dos produtores de Ploeg (2006): o produtor rentista, além de uma reformulação da hipótese de Schneider (2016): considerando aspectos contingenciais, acredita-se que a maior autonomia de um produtor dependerá da possibilidade de acessar o maior número de canais (ou pontos de vendas distintos dentro do mesmo canal), assim como, ter o controle para apropriar uma parcela maior do valor gerado, independentemente do número de canais.

Outra consideração é quanto ao enquadramento dos casos empíricos nos canais de comercialização. O canal de comercialização cooperativa, por exemplo, opera como um mercado local e territorial no caso de Santa Maria, mas, na classificação de Schneider (2006) aparece como mercado convencional. Essas informações de como as cooperativas comercializam a produção não surge do agricultor, mas de um conhecimento mais amplo, oriundo de estudos exploratórios com as próprias organizações. Ao mesmo tempo, sabe-se que no caso de Santa Maria essa Cooperativa comercializa com os mercados institucionais, fato que os 
agricultores não reconheceram no momento da entrevista. Desprezar esse tipo de informação do campo empírico pode fazer cair num equívoco de enquadramento.

\section{REFERÊNCIAS}

ABRAS. ABRAS divulga $1^{\circ}$ balanço do Programa de Rastreabilidade e Monitoramento de Alimentos (RAMA). Associação Brasileira de Supermercados. 2016. Disponível em: http://www.abras.com.br/supermercadosustent avel/segurancaalimentar/abras-divulga-10-balanco-do-programa-de-rastreabilidade-emonitoramento-de-alimentos-rama-2/ Acesso em 20 nov. 2016.

ACCORSI, R., FERRARI, E., GAMBERI, M., MANZINI, R., REGATTIERI, A. A ClosedLoop Traceability System to Improve Logistics Decisions in Food Supply Chains: A Case Study on Dairy Products. In: Advances in Food Traceability Techniques and Technologies (pp. 337-351). Woodhead Publishing. 2016. Disponível em: https://doi.org/10.1016/B978-0-08-100310-7.00018-1 Acesso em: jul. 2019.

ALLAOUI, H., GUO, Y., CHOUDHARY, A., BLOEMHOF, J. Sustainable agro-food supply chain design using two-stage hybrid multi-objective decision-making approach. Computers \& OperationsResearch, 89, 369. 2018. Disponível em: https://doi.org/10.1016/j.cor.2016.10.012 Acesso em: jul. 2019.

AHUMADA, O.; VILLALOBOS, J.R. Application of planning models in the agri-food supply chain: a review. European Journal of Operational Research. v.196, n.1, p.120. 2009.

BATALHA, M. O. Sistemas Agroindustriais: Definições e Correntes Metodológicas. In: Gestão Agroindustrial. Coord. BATALHA, M. O. v.1, São Paulo: Atlas, 1997.

BIMBO, F.; BONANNO, A.; NARDONE, G.; VISCECCHIA, R. The Hidden Benefits of Short Food Supply Chains: Farmers' Markets Density and Body Mass Index in Italy. InternationalFoodand Agribusiness Management Review. v.18, n.1, 2015.

BRANDÃO, J. B; ARBAGE, A. P. A gestão da cadeia de suprimentos das redes regionais de varejo de frutas, legumes e verduras no Rio Grande do Sul: um estudo multicaso. Extensão Rural, v. 23, n. 3, p. 51-68, 2016. Disponível em: https://periodicos.ufsm.br/extensaorural/article/view/18489 Acesso em: 30 mar. 2017.

BRANDÃO, J. B., ANVERSA, A.C.,; DREBES, L.M.. Terras arrendadas: suporte da produção de arroz irrigado no sul do Brasil. Acta Geográfica. set-dez2017, Vol. 11 Issue 27. 2017.

BRUNORI, G., GALLI, F., BARJOLLE, D., VAN BROEKHUIZEN, R., COLOMBO, L., GIAMPIETRO, M.; DE ROEST, K.. Are local food chains more sustainable than global 
food chains? Considerations for assessment. Sustainability, 8(5), 449. (2016). Disponível em: https://www.mdpi.com/2071-1050/8/5/449/htm Acesso julho de 2019.

CAMARGO, M.E.; PRIESNITZ FILHO, W.; SILVA, J.L.S.; MALAFAIA, G.C.; CRUZ, M. R.; MOTTA, M.E.V. Construção de cenários prospectivos em sistema agroalimentar de Vacaria, Rio Grande do Sul, Brasil. Agroalimentaria. v.20, n.38, p.137-149. 2014.

CASSOL, A.; SALVATE, N.; SCHNEIDER, S. Mercados Imersos: uma perspectiva de análise institucional e relacional das trocas econômicas e do intercâmbio mercantil. Política \& Sociedade, v. 15, n. 33, p. 314-346, 2016. Disponível em: https://periodicos.ufsc.br/index.php/politica/article/view/47772 Acesso em: ago. 2019.

COLDIRETTI, R.E. Vendita di vendita diretta: ecco i numeridi campagnaamica. 2012. Disponível em: http://www.reggio-emilia.coldiretti.it/vendita-diretta-ecco-i-numeridi-campagna-amica.aspx?KeyPub=GP_CD_REGGIOEMILIA_HOME\%7CCD_REGGIOEMILIA_HOME\&subski ntype=Detail\&Cod_Oggetto=32827709 Acesso em: 27 nov. 2016.

CONTERATO, M. ; NIEDERLE, P. A.; RADOMSKY, G. F.W.; SCHNEIDER, S. Mercantilização e mercados: a construção da diversidade da agricultura na ruralidade contemporânea. In: SCHNEIDER, S.; GAZOLLA,M.. (Org.). Os atores do Desenvolvimento Rural: perspectivas teóricas e práticas sociais. Porto Alegre: Editora da UFRGS, p. 67-89, 2011.

CUNHA, A.R.A.A. Dimensionando o passeio das mercadorias: uma análise através dos dados do Prohort. Revista Política Agrícola. n.4, p.55-63. 2015.

CUNHA, A. R. A. D. A.. Abastecimento alimentar: a superação do padrão velhoobsoleto para o novo-ancestral. SCHNEIDER, S.; CRUZ, F.; MATTE, A. Alimentos para produtores e consumidores: conectando novas estratégias de abastecimento de alimentos. Porto Alegre: Ed. da UFRGS, 54-70. 2016

DOWD, K.; BURKE, K.J. The influence of ethical values and food choice motivations on intentions to purchase sustainably sourced foods. Appetite. n.69, p.137-144. 2013.

FAVA NEVES, M. et al. Mapeamento e quantificação da cadeia produtiva de hortaliças .2017. Disponível em: http://www.favaneves.org/wpcontent/uploads/2018/03/Livro-Cadeia-Produtiva-Hortalicas-Marcos-Fava-NevesCNA-2017.pdf Acesso em: jul. 2019.

FORNAZIER, A.; BELIK, W. Produção e consumo local de alimentos: objetivos e debates. 2013. In: Anais do 51 Encontro da Sober. Belém, PA. Brasil. 2013.

GARG, S. K., SHARMA, M. K.; SHUKLA, M. IT/IS in supply chain management of agro industries. Management of innovation, technology, transfer \& flexibility for 
competitiveness in the globalized world. New Delhi, India: Global Institute of Flexible Systems Management. 2018. Disponível em:

http://www.indianjournals.com/glogift2k6/glogift2k6-1-1/theme_1/Article Acesso em: jul. 2019.

G1. Análise aponta mais agrotóxicos que o permitido em produtos da CEASA. Portal G1. Disponível em: http://g1.globo.com/rs/rio-grande-do-sul/noticia/2016/12/analiseaponta-mais-agrotoxicos-que-o-permitido-em-produtos-da-ceasa.html Acesso em: 15 mar. 2017.

GLOBAL AGRIBUSINESS FORUM - GAF Academy. Original Articles. 1 ed., 2014. Disponível em: http://docplayer.com.br/3541938-Global-agribusiness-forum-gafacademy-original-articles-various-authors-1st-edition-2014-sao-paulo-brazil-isbn-97885-68740-002.html Acesso em: nov. 2016.

GOODMAN, D. The quality "turn" and alternative food practices: reflections and agenda. Journal of Rural Studies, v. 19, n. 1, p. 1-7, 2003.

HASTUTI, E.Y. The influence of agribusiness system applied to vegetables farmers income improvement in Boyolali regency.

Dissertação(MestradoemDesenvolvimento Rural) - Diponegoro University. Semarang, 2007. Disponível em:

http://www.thomsonreuters.com/products_services/science/academic Acesso em: jul. 2019.

HAMZAOUI-ESSOUSSI, L.; SIRIEIX, L.; ZAHAF, M. Trust orientations in the organic food distribuition channels: a comparative study of the Canadian en French markets. Journal of Retailing and Consumer Services, v. 20, n. 3, p. 292-301, may. 2013.

HUGOS, Michael H. Essentials of supply chain management. John Wiley \& Sons, 2018.

KASRIEL-ALEXANDER, D. Top 10 Global Consumer Trends for 2016. Euromonitor International: London, UK, 2015.

KOTLER, P. Administração de marketing. São Paulo: Prentice-Hall, 2006.

KOTLER, P. Administração de marketing: análise, planejamento, implementação e controle. 5. ed. São Paulo: Atlas, 1998.

LAWRENCE, F. Not on the Label: What Really Goes into the Food on your Plate. London: Penguin. 2004.

LOURENZANI, A. E. B. S.; SILVA, AL da. Um estudo da competitividade dos diferentes canais de distribuição de hortaliças. Gestão e Produção, v. 11, n. 3, p. 385398, 2004. 
MALUF, R. Ações públicas locais de abastecimento alimentar. Polis Papers: Polis Assessoria, Formação e Estudos em Políticas Sociais. São Paulo. 42p. 1999.

MALUF, R. Mercados agroalimentares e a agricultura familiar no Brasil: agregação de valor, cadeias integradas e circuitos regionais. Ensaios FEE, Porto Alegre, v.25, n.1, p.299-322, abr. 2004.

MARTINEZ, S.M.; HAND, M.; Da PRA, S. et al. Local food systems: concepts, impacts, and issues. USDA Economic Research Report. n.97. Washington DC, US: USDA EconomicResearch Service. 2010.

MELO, P.C.; VILELA, N.J. A importância da Cadeia Produtiva Brasileira de Hortaliças. In: Sociedade Brasileira de Economia, Administração e Sociologia Rural. Rio Branco: Acre. 2007. Disponível em: http://www.abhorticultura.com.br/ downloads/cadeia_produtiva.pdf Acesso em: 17 out. 2016.

MELLO SOUZA, M. T., VILLANOVA, J. dos S., SILVA, G. P. da, BARRETO, R. M. Feirão da Gare: Uma nova perspectiva para a reterritorialização do sistema agroalimentar. In: Third International Conference on Agriculture and Food in an Urbanizing Society. Disponível em:

https://drive.google.com/file/d/oB7sGxomuriRtYmMoc2dGV3R4dWpEczVvRoVCOW VHcHdlTigo/view Acesso em: jul. 2019.

OJIMA, A. L. R. O.; SILVA, P. R. O papel da logística na cadeia de produção dos hortifrutis. 2005. Disponível em: http://www.iea.sp.gov.br Acesso em: fev. 2017.

O GLOBO. Greve de caminhoneiros já ameaça abastecimento no Sul. Jornal o Globo. Edição de 24 de fevereiro de 2015. Disponível em http://oglobo.globo.com/economia/greve-de-caminhoneiros-ja-ameacaabastecimento-no-sul-15421747 Acesso em: 23 nov. 2016.

PEREIRA, M. F. V. A inserção recente da cana-de-açúcar no sudoeste da Amazônia: novos indícios da instabilidade do território em Rondônia e Acre. Interações (Campo Grande), 11(2). (2016). Disponível em: http://www.scielo.br/pdf/inter/v11n2/a07v11n2 Acesso em: jul. 2019.

PLOEG, J. D. V. O modo de produção camponês revisitado. A diversidade da agricultura familiar, p. 13-54. Porto Alegre: Editora da UFRGS (Estudos Rurais), 2006.

PRIŠENK, J. et al. A multi-criteria assessment of the production and marketing systems of local mountain food. Renewable Agriculture and Food Systems. v.29, n.4, p.345-354, 2013.

ROESSING, A. C. Cadeias produtivas: roteiro para estudo de sistemas agroalimentares. Embrapa Soja-Documentos (INFOTECA-E). 2002. 
SANTA MARIA. Programas da Secretaria. Secretaria Municipal de Desenvolvimento Rural de Santa Maria. Disponível em: http://www.santamaria.rs.gov.br/rural/68programas-da-secretaria Acesso em: mar. 2017.

SAZVAR, Z., RAHMANI, M., GOVINDAN, K. A sustainable supply chain for organic, conventional agro-food products: The role of demand substitution, climate change and public health. Journal of cleaner production, 194, 564-583. 2018. Disponível em: https://doi.org/10.1016/j.jclepro.2018.04.118 Acesso em: jul. 2019.

SCARABELOT, M.; SCHNEIDER, S. As cadeias agroalimentares curtas e desenvolvimento local - um estudo de caso no município de Nova Veneza / SC. Revista Faz Ciência FC, 14 (19), 101 -130. jan/jul 2012. Disponível em: http://erevista.unioeste.br/index.php/fazciencia/article/view/8028/8030 Acesso em julho de 2019.

SCHNEIDER, S. Agricultura Familiar e Mercados. In: MARQUES, F. C.; CONTERATO, M. A.; SCHNEIDER, S. (Org.) Construção de Mercados e Agricultura Familiar: Desafios para o Desenvolvimento Rural. 1. ed. Porto Alegre: UFRGS, 2016. 416p.

SCHERMER, M. De. Food from Nowhere" a "Food from Here: mudando as relações produtor-consumidor na Áustria. Agriculture and Human Values, 32 (1), 121-132. 2015. Disponível em: https://link.springer.com/article/10.1007/s10460-014-9529-z Acesso em julho de 2019.

SHULTZ, Glauco; DE SOUZA, Marcelino; JANDREY, Willian Fontanive. Motivações e acesso aos canais de comercialização pelos agricultores familiares que atuam com produção orgânica na Região da Serra Gaúcha. Redes (St. Cruz Sul, Online), Santa Cruz do Sul, v. 22, n. 3, p. 273-291, set. 2017. ISSN 1982-6745. Disponível em: https://online.unisc.br/seer/index.php/redes/article/view/7627 Acesso em: jul. 2019. doi: https://doi.org/10.17058/redes.v22i3.7627

SINI, P. Long and Short Supply Chain Co-existence in the Agricultural Food Market on Different Scales: Oligopolies, Local Economies and the Degree of Liberalisation of the Global Market. European Scientific Journal. v.10, n.4, 2014.

SILVA, L. S. D. Do acampamento da seca ao programa camponês: atuais contribuições do MPA no processo político-social do Nordeste e seu campesinato à luz do contexto agrário.Dissertação de mestrado. (Mestrado em Desenvolvimento territorial na América Latina e Caribe). Universidade Estadual Paulista, São Paulo, 2017. Disponível em: http://hdl.handle.net/11449/158266 Acesso em: jul. 2019.

SOUZA FILHO, H. M.; BONFIM, R. M. Oportunidades e desafios para a inserção de pequenos produtores em mercados modernos. In: CAMPOS, S. K.; NAVARRO, Z. A pequena produção rural e as tendências do desenvolvimento agrário brasileiro: Ganhar tempo é possível? Brasília - DF: Embrapa. 2013. 264 p. 
SYROVÁTKOVÁ, M.; HRABÁK, J.; SPILKOVÁ, J. Farmers' markets' locavore challenge: The potential of local food production for newly emerged farmers' markets in Czechia. Renewable Agriculture and Food Systems. v.30, n.4, p.305-317, 2014.

SPROESSER, R. L.; LIMA FILHO, D. O. Varejo de alimentos: estratégia e marketing. In: BATALHA, M.O. Gestão agroindustrial. 3. ed. São Paulo: Atlas, 2007.

SOTO-SILVA, W. E., NADAL-ROIG, E., GONZÁLEZ-ARAYA, M. C.; PLA-ARAGONES, L. M. Operationalresearchmodelsapplied to thefresh fruit supply chain. European Journal of Operational Research, 251(2), 345-355. 2016. Disponível em: https://doi.org/10.1016/j.ejor.2015.08.046 Acesso em: jul. 2019.

SWENSSON, L. F. Institutional food procurement programmes and producer organizations: catalysts for the transformation of small-scale producers' food supply systems. REDES: Revista do Desenvolvimento Regional, 24(1), 30-44. 2019. Disponível em: http://dx.doi.org/10.17058/redes.v24i1.13041 Acesso em: out. 2019.

VASILE, M., e DA CRUZ, F. T. Identity-construction, mutual enskilment and political negotiation at the farmers' market. REDES: Revista do Desenvolvimento Regional, 24(1), 212-226. 2019. Disponível em: http://dx.doi.org/10.17058/redes.v24i1.13043 Acesso em: out. 2019.

WAQUIL, P. D.; MIELE, M. e SCHULTZ, G. Mercados e Comercialização de Produtos Agrícolas. Porto Alegre: Editora da UFRGS, 2010.

WILKINSON, J. Mercados, redes e valores: o novo mundo da agricultura familiar. Porto Alegre: UFRGS, 2008.

ZEITUNE, C. R. Conceitos das CEASAs. In: ABRACEN. Manual Operacional das CEASAs do Brasil. Belo Horizonte: AD2 Editora, 2011. P. 9-13.

ZYLBERSZTAJN, D.; Conceitos Gerais, Evolução e Apresentação do Sistema Agroindustrial. In: ZYLBERSZTAJN, D.; NEVES, M. F. (Org.) Economia e Gestão dos Negócios Agroalimentares. São Paulo: Pioneira. 2000.

Janaína Balk Brandão. Doutora em Extensão Rural. Universidade Federal de Santa Maria. Professora. janainabalkbrandao@hotmail.com

Sérgio Schneider. Doutor em Sociologia. Universidade Federal do Rio Grande do Sul.Professor.schneide@ufrgs.br

Humberto Davi Zen. Mestre em Extensão Rural. Universidade Federal de Santa. Estudante. humbertozen@gmail.com

Gustavo Pinto da Silva. Doutor em Extensão Rural. Universidade Federal de Santa Maria.Professor.gustavo.pinto@politecnico.ufsm.br 
Como citar: BRANDÃO, Janaína Balk et al. Os mercados de hortifrúti em Santa Maria (RS) um estudo sobre os tipos de produtores e os canais de comercialização. Redes (St. Cruz Sul, Online), Santa Cruz do Sul, v. 25, n. 2, p. 433-460, abr. 2020. ISSN 1982-6745. Disponível em: https://doi.org/10.17058/redes.v25i2.14323

\section{CONTRIBUIÇÃO DE CADA AUTOR}

a. Fundamentação teórico-conceitual e problematização: Sérgio Schneider; Janaína Balk Brandão;

b. Pesquisa de dados e análise estatística: Humberto Davi Zen.

c. Elaboração de figuras e tabelas: Humberto Davi Zen; Janaína Balk Brandão.

d. Elaboração e redação do texto: Humberto Davi Zen; Janaína Balk Brandão; Gustavo Pinto da Silva

e. Seleção das referências bibliográficas: Sérgio Schneider; Janaína Balk Brandão;

Fontes de financiamento: Fundo de Incentivo a Pesquisa (FIPE). Universidade Federal de Santa Maria. 